\title{
Transcription factor decoy against NFATc1 in human primary osteoblasts
}

\author{
LETIZIA PENOLAZZI $^{1}$, GINA LISIGNOLI ${ }^{2}$, ELISABETTA LAMBERTINI ${ }^{1}$, ELENA TORREGGIANI ${ }^{1}$, \\ CRISTINA MANFERDINI ${ }^{2}$, ANDREA LOLLI ${ }^{1}$, RENATA VECCHIATINI ${ }^{1}$, FRANCESCA CIARDO ${ }^{1}$, \\ ELENA GABUSI $^{2}$, ANDREA FACCHINI $^{2}$, ROBERTO GAMBARI $^{1}$ and ROBERTA PIVA ${ }^{1}$ \\ ${ }^{1}$ Dipartimento di Biochimica e Biologia Molecolare, Sezione di Biologia Molecolare, Università degli \\ Studi di Ferrara, Ferrara; ${ }^{2}$ Struttura Complessa Laboratorio di Immunoreumatologia \\ e Rigenerazione Tissutale, Istituto Ortopedico Rizzoli, Bologna, Italy
}

Received November 24, 2010; Accepted January 14, 2011

DOI: 10.3892/ijmm.2011.701

\begin{abstract}
The present study describes, for the first time, the removal of the nuclear factor of activated $\mathrm{T}$ cells cytoplasmic 1 (NFATc1) by a decoy approach in human primary osteoblasts (hOBs). hOBs with different NFATc1 expression levels were used. The functionality of endogenous NFAT proteins in our experimental model was analyzed by monitoring the transcriptional activity on a luciferase reporter construct driven by three copies of an NFAT response element (pNFAT-TA-luc). Cell treatment with the decoy against NFATc1 resulted in a significant increase in the expression of osteoblastic markers, including ER $\alpha$ and ColXV. On the contrary, the expression of Runx2, which is known to not be transcriptionally regulated by NFATc1, was not altered, indicating the specificity of the decoy effect. To our knowledge, this is the first time that transcription factor decoy has been successful in hOBs to allow the investigation of the role of NFATc1 in an experimental model that, compared to the use of cell lines, more closely resembles an in vivo model. In addition, by using chromatin immunoprecipitation we found that in vivo NFATc1 is recruited on the ColXV gene promoter. The specific role of NFATc1 in osteoblast differentiation is not well understood, however, our findings reinforce the action of NFATc1 in the transcriptional program of osteoblasts, also supporting the therapeutic potential for the proper manipulation of NFATc1mediated events in different bone disorders. At the same time, our data add important information on the regulation of the expression of ColXV, which only recently has been proposed as an osteoblastic marker.
\end{abstract}

Correspondence to: Professor Roberta Piva, Dipartimento di Biochimica e Biologia Molecolare, Sezione di Biologia Molecolare, Via Fossato di Mortara 74, I-44121 Ferrara, Italy

E-mail: piv@unife.it

Key words: nuclear factor of activated $\mathrm{T}$ cells, collagen type XV, transcription factor decoy, human primary osteoblasts, chromatin immunoprecipitation

\section{Introduction}

Modulation of the activities of bone-forming osteoblasts and bone-resorbing osteoclasts is one of the major therapeutic objectives in a variety of bone tissue diseases $(1,2)$. As a therapeutic target for modulation of bone remodeling, the nuclear factor of activated $\mathrm{T}$ cells (NFAT) has recently received considerable attention, even if many reports describe the importance of the NFAT-mediated signaling in the control of both bone resorption and bone formation with contradictory findings (3-8).

NFAT proteins comprise a family of transcription factors (NFAT 1-5) that, after calcium/calcineurin-dependent dephosphorylation, are activated and regulate the expression of many genes involved in a wide range of cellular processes (9-11). NFAT proteins are capable of forming strong cooperative complexes with related transcription factors such as $\mathrm{NF}-\kappa \mathrm{B}$ proteins, and unrelated binding partners such as GATA, Maf, Oct, PPAR- $\gamma$, and members of the AP-1 family on composite cis elements $(1,12-15)$.

To gain insight into the role of NFAT proteins in the bone, and in the search for novel NFAT target genes in osteoblasts, we analyzed the effect of the inhibition of NFATc1 function, through a specific decoy approach, in human primary osteoblasts (hOBs). The transcription factor decoy (TFD) strategy is a kind of gene silencing approach aimed at eliminating or attenuating the activity of a specific transcription factor (16-23). TFD is based on the cellular transfection of double-stranded DNA oligonucleotides (ODNs) mimicking the cis-element that is recognized by the transcription factor, and transcription factor binding on endogenous target genes is quickly and effectively blocked. Therefore, the decoy approach is a powerful tool for interfering with the activity of a specific transcription factor and for modulating transcription of its target genes. To our knowledge, this is the first time that TFD has been successfully used in hOBs to investigate the role of NFATc1 in an experimental model which, compared to the use of cell lines, more closely resembles an in vivo model.

Our previous study identified NFATc1 as negative regulator of the estrogen receptor $\alpha(\mathrm{ER} \alpha)$ gene transcription in 
the SaOS-2 osteosarcoma cell line (24). Considering that ER $\alpha$ plays an important positive role in the control of proliferation, differentiation, and survival of osteoblasts (25), our previous data (24) led us to more thoroughly investigate the effect of NFATc1 inhibition in hOBs, an experimental model more easily associated with an in vivo context.

\section{Materials and methods}

Isolation and culture of osteoblasts. Bone tissues were harvested from ten elderly patients undergoing total knee

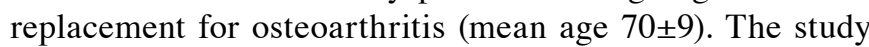
was approved by the local Ethics Committee and informed consent was obtained from each patient.

Trabecular bone was obtained from the inner portion of the tibial plateau. Bone chips were removed from the tibial plateau, collected in a V-glass tube containing $1.5 \mathrm{ml}$ of $\alpha$-MEM supplemented with $15 \%$ FBS, $25 \mathrm{mg} / \mathrm{ml}$ ascorbic acid and penicillin G (Sigma, St. Louis, MO, USA) (referred as $\alpha$-MEM medium).

Transient transfections and the luciferase assay. Transient transfections were performed on cells grown to $60 \%$ confluency, in 24-well plates with $\alpha$-MEM medium plus $10 \% \mathrm{FBS}$, using Lipofectamine reagent (Invitrogen Corp., Carlsbad, CA, USA), according to the manufacturer's instructions. Cells were transfected with a total of $1 \mu \mathrm{g} / \mathrm{ml}$ of ODN-decoy complexed with $3 \mu \mathrm{g}$ of Lipofectamine $24 \mathrm{~h}$ after the seeding (first administration); on day 4 , the cells were further transfected with the same DNA amount until day 7, when the cells were harvested.

For transfection experiments with pNFAT-TA-luc or empty vectors, the cells were plated in 24-well plates, maintained in $\alpha$-MEM medium with $10 \% \mathrm{FBS}$, in the presence of different amounts of $\mathrm{CaCl}_{2}(0.5,1.3,2.6 \mathrm{mM})$ and in the presence of $0.5 \mu \mathrm{M}$ ionomycin and $100 \mu \mathrm{g} / \mathrm{ml} \mathrm{PMA}$ (Sigma). After $24 \mathrm{~h}$ the cells were transiently transfected using Lipofectamine reagent (Invitrogen Corp.) with $5 \mu \mathrm{g}$ of plasmid vector. After overnight incubation, the medium was removed and fresh medium was added. After another $24 \mathrm{~h}$, the cells were harvested, lysed, and assayed for luciferase activity. The luciferase activity was normalized by the total protein amount and by $\beta$-galactosidase values resulting from co-transfection of $0.25 \mu \mathrm{g}$ of pCMVSport $\beta$-gal (Invitrogen Corp.). $\beta$-galactosidase activity was measured by using the Beta-Glo Assay System (Promega, WI, USA).

Chromatin immunoprecipitation (ChIP) assay. The ChIP assay was carried out as previously described (26) using the standard protocol supplied by Upstate Biotechnology (Lake Placid, NY) with their ChIP assay reagents. The cells were cross-linked with $1 \%$ formaldehyde for $10 \mathrm{~min}$ at $37^{\circ} \mathrm{C}$, washed in ice-cold PBS, and suspended in SDS lysis buffer for $10 \mathrm{~min}$ on ice. Samples were sonicated, diluted 10-fold in dilution buffer supplemented with protease inhibitors, and precleared with $80 \mu \mathrm{l}$ of DNA-coated protein A-agarose; the supernatant was used directly for immunoprecipitation with $10 \mu \mathrm{g}$ of anti-NFATc1, (H-110) (Santa Cruz Biotechnology, Santa Cruz, CA, USA), overnight at $4^{\circ} \mathrm{C}$. Immunocomplexes were mixed with $80 \mu \mathrm{l}$ of DNA-coated protein A-agarose followed by incubation for $1 \mathrm{~h}$ at $4^{\circ} \mathrm{C}$. Beads were collected and sequentially washed 3 times with $1 \mathrm{ml}$ each of the following buffers, low salt wash buffer $(0.1 \%$ SDS, $1 \%$ Triton X-100, $2 \mathrm{mM}$ EDTA, $20 \mathrm{mM}$ Tris- $\mathrm{HCl} \mathrm{pH} 8.1,150 \mathrm{mM} \mathrm{NaCl}$ ), high salt wash buffer $(0.1 \%$ SDS, $1 \%$ Triton X-100, 2 mM EDTA, $20 \mathrm{mM}$ Tris- $\mathrm{HCl} \mathrm{pH} 8.1,500 \mathrm{mM} \mathrm{NaCl}), \mathrm{LiCl}$ wash buffer (0.25 mM LiCl, 1\% Igepal CA630, 1\% deoxycholic acid, $1 \mathrm{mM}$ EDTA,10 mM Tris pH 8.1), and TE buffer. The immunocomplexes were eluted two times by adding a $250 \mu \mathrm{l}$ aliquot of a freshly prepared solution of $1 \% \mathrm{SDS}, 0.1 \mathrm{M} \mathrm{NaHCO}_{3}$ and the cross-linking reactions were reversed by incubation at $65^{\circ} \mathrm{C}$ for $4 \mathrm{~h}$. The samples were then digested with proteinase $\mathrm{K}$ $(10 \mathrm{mg} / \mathrm{ml})$ at $45^{\circ} \mathrm{C}$ for $2 \mathrm{~h}$ and DNA was purified by Qiaquick Spin Columns (Qiagen Inc., Germantown, MD). For PCR analysis, aliquots of chromatin before immunoprecipitation were saved (Input). PCR was performed to analyze the presence of DNA precipitated by the NFATc1-specific antibody, and by using specific primers (Table I) to amplify fragments of the collagen type XV (ColXV) gene promoter. Each PCR reaction was performed with $5 \mu \mathrm{l}$ of the bound DNA fraction or $2 \mu \mathrm{l}$ of the Input. The PCR was performed as follows, preincubation at $95^{\circ} \mathrm{C}$ for $5 \mathrm{~min}, 30$ cycles of 1 min denaturation at $95^{\circ} \mathrm{C}, 1 \mathrm{~min}$ annealing at $52^{\circ} \mathrm{C}$ and $1 \mathrm{~min}$ at $72^{\circ} \mathrm{C}$, with one final incubation at $72^{\circ} \mathrm{C}$ for $5 \mathrm{~min}$. A no-antibody control was included in each experiment.

Electrophoretic mobility shift assay (EMSA). Nuclear extracts from Jurkat cells were prepared as previously described (27). Double-stranded oligonucleotides were end-labeled with $\left[\gamma-{ }^{32} \mathrm{P}\right]-\mathrm{ATP}$ and T4 polynucleotide kinase (GE Healthcare, Germany). For the gel shift assay $10 \mu \mathrm{g}$ of nuclear proteins were pre-incubated for $5 \mathrm{~min}$ at room temperature with $1.2 \mu \mathrm{g}$ of non-specific competitor DNA poly(dI-dC)-(dI-dC) (Pharmacia Corp., Bridgewater, NJ) and then 10,000 cpm of labeled oligonucleotides were added and incubated for another $30 \mathrm{~min}$ at room temperature. For the competition experiments a 50- and 100-fold excess of unlabeled oligonucleotides was incubated with the nuclear extracts for $15 \mathrm{~min}$ at room temperature and then incubated with the appropriate ${ }^{32} \mathrm{P}$-labeled DNA probe. For supershift experiments, nuclear extracts were pre-incubated for $15 \mathrm{~min}$ at room temperature with $4 \mu \mathrm{g}$ of the antibody against NFATc1 prior to their 30 min incubation with the labelled oligonucleotides at room temperature. Reactions were run on $6 \%$ polyacrylamide gels and electrophoresed at $150 \mathrm{~V}$ for $2 \mathrm{~h}$ in $0.5 \mathrm{X}$ TBE buffer. Gels were then dried and exposed to film at $-80^{\circ} \mathrm{C}$.

Immunocytochemistry. Cells grown in chamber slides were fixed in 4\% PFA for $20 \mathrm{~min}$ at room temperature and then hydrated with TBS $1 \% \mathrm{BSA}$ for $5 \mathrm{~min}$ at room temperature. The slides were incubated with the monoclonal antibodies: anti-human-Runx2, anti-osteocalcin (OC; R\&D Systems, Minneapolis, MN), anti-bone sialoprotein (BSP; Fisher Scientific, Pittsburg, PA, USA), anti-collagen type 1 (Col1A1; obtained from DSHB, Department of Biological Sciences, Iowa City, IA), anti-NFATc1 (Santa Cruz Biotechnology) and anti-ER $\alpha$ (Upstate Biotechnology), for $1 \mathrm{~h}$ at room temperature. The slides were washed three times with TBS 1\% BSA and then sequentially incubated with multilinker biotinylated secondary antibody and alkaline phosphatase-conjugated 
Table I. PCR primers used for the chromatin immunoprecipitation assay (ChIP) on the ColXV gene.

Primer sequences

Product size (bp)

\begin{tabular}{ll}
\hline Forward F1 & 5'-TCCACTCCTGGGCATTCAAG-3' \\
Reverse R1 & 5'-GACGGAATACATTGGACGCT-3' \\
Forward F2 & 5'-TTACTGGCAGGCAGCATGGCT-3' \\
Reverse R2 & 5'-CACAAACTAAGTCAAGGTGAGAT-3' \\
Forward F3 & 5'-CACAGGGAATGTGAACAGATT-3' \\
Reverse R3 & 5'-AGAACGGGAACCAGACTAAA-3' \\
Forward F4 & 5'-CATGTTCTTCTCCCCATATATC-3' \\
Reverse R4 & 5'-AACTCTGAAGACCTAAGAAAAACT-3' \\
\hline
\end{tabular}

streptavidin (BioGenex kit, San Ramon, CA, USA) or goat anti-rabbit HRP (DakoCytomation), at room temperature for $20 \mathrm{~min}$. The slides were developed using fast red as a substrate or a peroxidise reaction using 3,3'-diaminobenzidine as a substrate, counterstained with haematoxylin, mounted with glycerol jelly and and observed using a Leitz microscope. Negative and isotype matched controls were performed.

Mineralization assay. The extent of mineralized matrix in the plates was determined by Alizarin Red S staining (ARS; Sigma) in the cells cultured for up to 21 days in osteogenic medium consisting of DMEM, high-glucose, supplemented with $10 \%$ FBS, $10 \mathrm{mM} \beta$-glycerophosphate, $0.1 \mu \mathrm{M}$ dexamethasone, and $50 \mathrm{mM}$ ascorbate (Sigma). In the committed cells, the osteogenic medium was changed every 3 days. The cells were then fixed in $70 \%$ ethanol for $1 \mathrm{~h}$ at room temperature, washed with PBS, stained with $40 \mathrm{mM}$ ARS (pH 4.2) for $10 \mathrm{~min}$ at room temperature, washed five times with deionized water, and incubated in PBS for $15 \mathrm{~min}$ to eliminate nonspecific staining. The stained matrix was observed at different magnifications using a Leitz microscope.

Real-time quantitative RT-PCR. For RT-PCR analysis, totalRNA was isolated from hOBs using a total-RNA isolation system (RNeasy Plus Micro kit, Qiagen, Italy). Total-RNA $(2 \mu \mathrm{g})$ was reverse transcribed with the ImProm-II RT System (Promega). The mRNA of the target genes was quantified by real-time PCR using the ABI Prism 7700 system and TaqMan probes for Runx-2, ER $\alpha$ and ColXV (Applied Biosystems, CA, USA). PCR was carried out in a final volume of $25 \mu \mathrm{l}$ after a 10 min pre-incubation at $95^{\circ} \mathrm{C}$ (denaturation), $1 \mathrm{~min}$ at $60^{\circ} \mathrm{C}$ (annealing/elongation). The mRNA levels were corrected for GAPDH mRNA levels (reference gene) and normalized to a calibrator sample (control cells).

Calcium measurements. Basal levels of the cytoplasmic $\mathrm{Ca}^{2+}$ concentration were measured in Fura-2-AM-loaded cells as previously described (28). Cells were grown on $24 \mathrm{~mm}$ coverslips in $\alpha$-MEM medium supplemented with $1 \%$ FBS and loaded with 4-AM Fura-2-AM (added to KRB/ $\mathrm{Ca}^{2+}$ solution $+1 \% \mathrm{FBS}$ ) at $37^{\circ} \mathrm{C}$ for $30 \mathrm{~min}$. The coverslip was washed and transferred to the thermostated stage of a Zeiss Axiovert 200 inverted microscope, equipped with a Sutter filterwheel and 340/380 excitation filters. The sample was excited at 340 and $380 \mathrm{~nm}$ using a random access monochromator (Photon Technology International, NJ, USA) and emission was detected using a 505/30 emission filter. Images were acquired every $3 \mathrm{sec}$ by the BFT512 camera (Princeton Instruments, AZ, USA). Image acquisition was controlled by the MetaFluor 5.0 software (Universal Imaging Corp., PA, USA). Calibration was performed using the MetaFluor and the MetaFluor Analyst software, according to the equation $\left[\mathrm{Ca}^{2+}\right]=\mathrm{K}_{\mathrm{d}} \times(\mathrm{Sf} 2 / \mathrm{Sb} 2) \times\left(\mathrm{R}-\mathrm{R}_{\min }\right) /\left(\mathrm{R}_{\max }-\mathrm{R}\right)$, where $\mathrm{K}_{\mathrm{d}}=224 \mathrm{nM} . \mathrm{R}_{\max }$ and $\mathrm{R}_{\min }$ were determined at the end of each experiment in $\mathrm{KRB} / \mathrm{Ca}^{2+} / 1 \mu \mathrm{M}$ ionomycin, and $\mathrm{KRB} / 1 \mathrm{mM}$ EGTA/ ionomycin, respectively.

Statistical analysis. Data are presented as the mean \pm SEM from at least three independent experiments, where indicated. Statistical analysis was performed by one-way analysis of variance followed by the Student's t-test. A P-value $<0.05$ was considered statistically significant.

\section{Results}

Characterization of primary osteoblast cultures. hOBs were generated from bone chips removed from the tibial plateau as previously described (29) and characterized for the typical osteogenic markers. In Fig. 1A the analysis of a representative sample of the cells that we used is shown. The cells were highly positive for Runx2, Col1A1, BSP and OC, and exhibited an evident extracellular matrix mineralization after 21 days of culture under osteogenic conditions (ARS). In addition, the cells were positive for $\mathrm{ER} \alpha$, a transcription factor strictly associated with osteoblast differentiation, and for NFATc1, the target of our decoy treatment, as demonstrated by immunocytochemical analysis and quantitative RT-PCR (Fig. 1B).

NFATcl binds to the decoy ODN molecule. We used the EMSA to analyze NFATc1 binding to the decoy ODN, which contains one NFAT motif (24). Proteins from the nuclear extract of Jurkat, a highly NFATcl positive human T-leukemia cell line, efficiently bound to the decoy ODN probe, giving two major retarded complexes (Fig. 2). The labeled retarded complexes were found to be specifically out-competed by increasing concentrations of cold excess of decoy ODN, while they were unaffected by a 100-fold excess of an unrelated 
$\mathbf{A}$
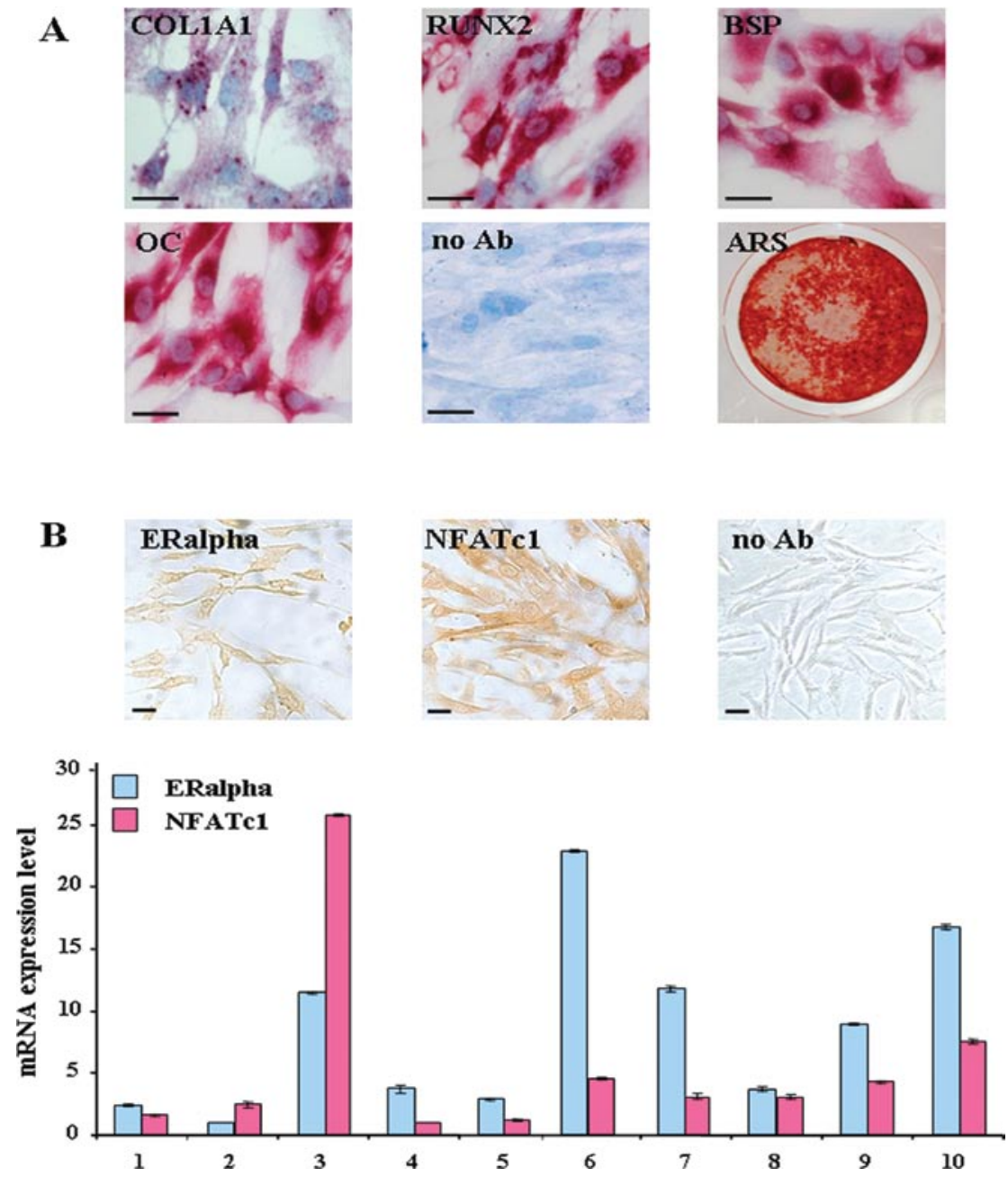

Figure 1. Phenotypical characterization of hOBs. (A) Ten hOB samples were subjected to immunocytochemical analysis for collagen type 1 (Col1A1), Runx2, bone sialoprotein (BSP) and osteocalcin (OC). Mineral matrix deposition was analyzed by Alizarin Red staining (ARS). The staining shows the local expression of the markers analyzed in a representative sample (x40 magnification; bar denotes $20 \mu \mathrm{m}$ ). (B) The same samples were analyzed for ER $\alpha$ and NFATc1 by immunocytochemistry [a representative sample and a negative control (no Ab) are shown, x20 magnification; bar denotes, $20 \mu \mathrm{m}$ ], and quantitative RT-PCR. The mRNA expression levels were normalized on the basis of GAPDH expression and the $\Delta \Delta \mathrm{Ct}$ method was used to compare gene expression data; the means and standard error of the means (SEM) were calculated.

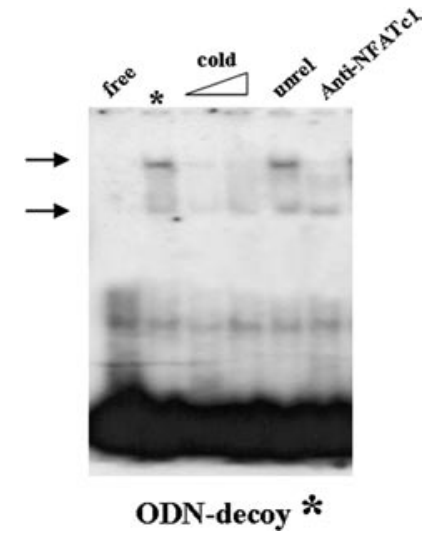

Figure 2. A gel shift experiment was performed with nuclear extracts from Jurkat cells in the presence of ${ }^{32} \mathrm{P}$-labeled ODN-decoy oligonucleotide against NFATc1. Protein DNA complexes were resolved from the free probe on a non-denaturing $6 \%$ polyacrylamide gel. A representative gel is shown. The ${ }^{32} \mathrm{P}$-labeled oligonucleotide was incubated alone (free), in combination with $10 \mu \mathrm{g}$ of nuclear extracts $(*)$, and in the presence of 50 - and 100 -fold molar excess of specific unlabeled oligonucleotide (cold), or unrelated oligonucleotide (unrel). An antibody against NFATc1 $(4 \mu \mathrm{g})$ was also incorporated into the binding reaction (anti-NFATc1). The main retarded complexes are indicated by arrows. oligonucleotide, demonstrating the specificity of these DNA protein interactions. The upper band was abolished when an anti-NFATc1 antibody was added, confirming that NFATc1 was present in this retarded complex.

Analysis of NFAT activity. The functionality of the endogenous NFAT proteins in our experimental model were analyzed by monitoring the transcriptional activity on a luciferase reporter construct driven by three copies of an NFAT response element (pNFAT-TA-luc). As shown in Fig. 3A, NFAT-driven luciferase activity in all transfected hOBs cultured in the presence of ionomycin and PMA, was remarkable and positively correlated with calcium levels, demonstrating the ability of endogenousactivated NFAT to bind the specific cis-acting elements in these cells. The presence of NFAT-driven luciferase activity was also found in hOBs cultured in medium without ionomycin and PMA in the absence of exogenous calcium (Fig. 3B), suggesting that the intracellular calcium may be sufficient to activate NFAT proteins. The calcium mobilization ability of hOBs was demonstrated through accurate measurements of 
A
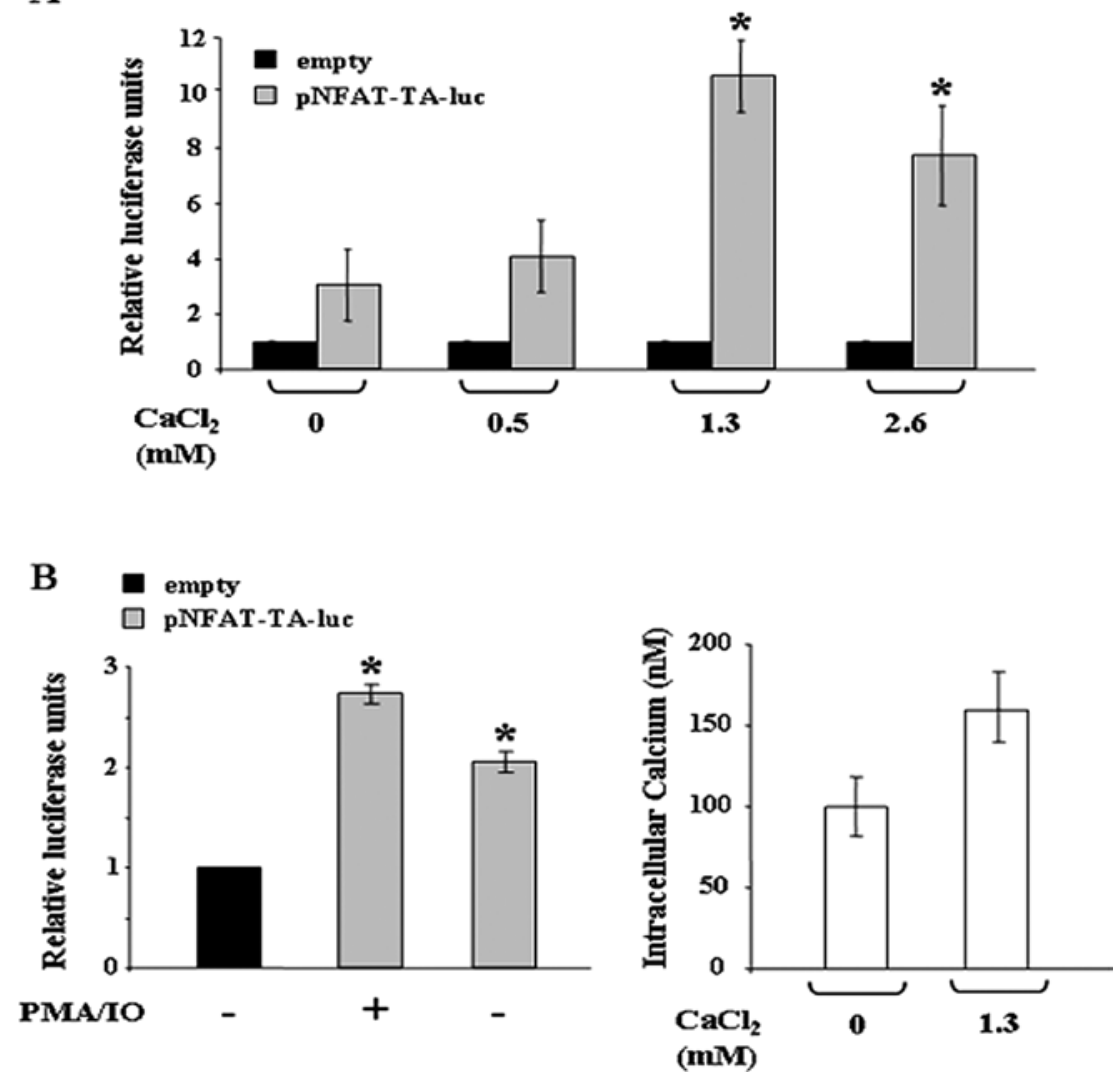

Figure 3. NFAT reporter gene assay. (A) Five different hOB samples were transiently transfected with pNFAT-TA-luc or empty vector in four different culture medium conditions, $0,0.5,1.3$ and $2.6 \mathrm{mM} \mathrm{CaCl}_{2}$, in the presence of $0.5 \mu \mathrm{M}$ ionomycin and $100 \mu \mathrm{g} / \mathrm{ml}$ PMA. The results were normalized to the protein concentration and $\beta$-galactosidase activity for the transfection efficiency and represent the average of five different experiments performed in duplicate. The data are expressed as the mean \pm SEM and indicated as fold-inductions over the empty vector. ${ }^{~} \mathrm{P}<0.05$ vs. $0 \mathrm{mM}$. (B) The same protocol was applied for hOBs cultured in $\alpha$-MEM $10 \%$ FBS, in the presence (+) or in the absence (-) of $0.5 \mu$ M ionomycin (IO) and $100 \mu \mathrm{g} / \mathrm{ml}$ PMA treatment before pNFAT-TA-luc transient transfection. ${ }^{*} \mathrm{P}<0.05$ vs. empty vector. The basal intracellular $\mathrm{Ca}^{2+}$ concentrations $(\mathrm{nM})$ in hOBs was measured (diagram at the right). Cells were grown in the absence (0) and in the presence of $1.3 \mathrm{mM} \mathrm{CaCl}_{2}$ medium on coverslips, then loaded with Fura-2-AM and analyzed as reported in Materials and methods. The average and the SEM of all recorded data are reported.

intracellular calcium release in the absence or presence of exogenous calcium in Fura-2-AM-loaded cells (Fig. 3B).

The effect of the decoy against NFATcl. The cells were plated at $60 \%$ confluence, and after $24 \mathrm{~h}$ a first administration of NFATc1 decoy ODN or scrambled ODN was performed. A second administration was applied on day 4 before cell harvesting on day 7 for the molecular analysis (scheme at the top of Fig. 4).

On the basis of the results reported in Fig. 3, we performed decoy experiments in hOBs cultured in $\alpha$-MEM medium and left untreated with ionomycin and PMA. This allowed the estimation of the decoy effect at basal conditions in the absence of the calcium mobilization induced by the phorbol ester, PMA, and the ionomycin calcium ionophore.

We first examined the efficiency of hOBs treatment with the NFATc1 decoy ODN by analyzing the expression of the $\mathrm{ER} \alpha$ gene by quantitative RT-PCR. In fact, we previously demonstrated that in different cell lines this decoy treatment induced a significative increase of $\mathrm{ER} \alpha$ gene expression because NFATc1 acts as negative regulator of ER $\alpha$ gene transcription. As shown in Fig. 4, decoy against NFATc1, but not scrambled oligonucleotide, increased the expression of ER $\alpha$ confirming the specific role of NFATc1. We then turned our attention to the expression pattern of Runx2, the master regulator of osteoblastogenesis that is not transcriptionally regulated by NFATc1 (5), and of ColXV, a recently investigated novel marker of osteoblast differentiation whose expression is regulated by exogenous calcium addition (30). The data are reported in Fig. 4. As expected, the functional inactivation of NFATc1 did not affect Runx2 expression indicating the specificity of the decoy effect. On the contrary, a significant increase of ColXV expression was found in the decoy-treated cells. Using a program for predicting transcription factor binding sites (TFSEARCH, www.cbrc.jp/ research/db/TFSEARCH.html), we found that 5 ' regulatory regions of all three genes analyzed contain potential binding sites (5'-GGAAA-3'), for NFATc1. However, only ER $\alpha$ and ColXV but not Runx2 seem to be critical downstream targets of NFATc1.

NFATc1 interacts in vivo with the promoter of the ColXV gene. We then focused our attention on the poorly studied ColXV gene promoter by investigating in vivo NFATc1 recruitment by ChIP binding assays (Fig. 5). To this aim, we employed four hOB samples that were treated with PMA/ionomycin to ensure full NFAT induction. hOBs were exposed to formaldehyde to cross-link proteins and 

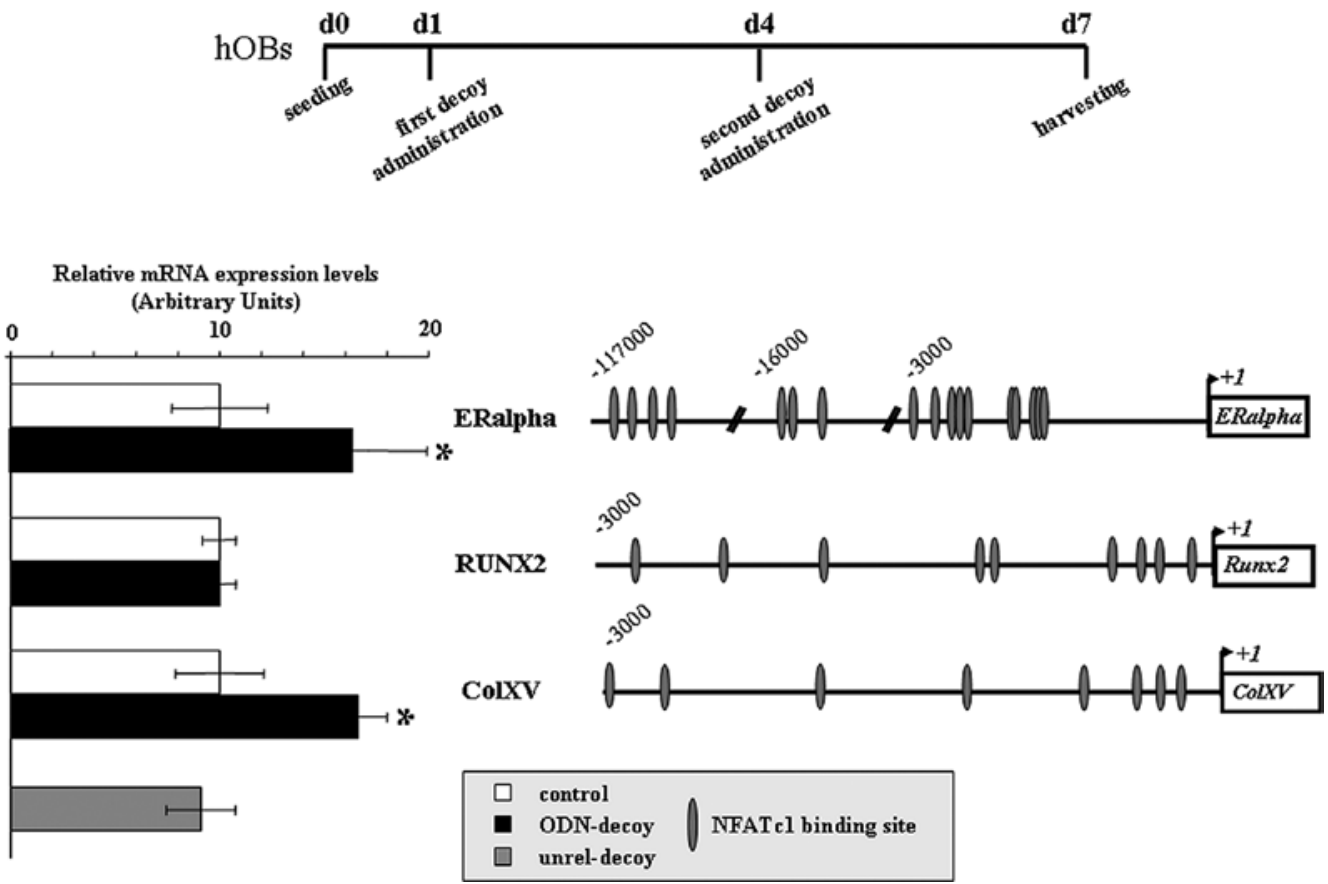

Figure 4. Analysis of ER $\alpha$, Runx2 and ColXV expression by quantitative RT-PCR after decoy against NFATc1. Ten hOB samples were cultured up to 7 days with $1 \mu \mathrm{g} / \mathrm{ml}$ of ODN-decoy administered in two different steps, as indicated in the scheme above. The expression levels were normalized on the basis of GAPDH expression and results of the experiments are reported as relative mRNA expression levels over the control cells. Arbitrary units are used for the attribution of the fold inductions. The $\Delta \Delta \mathrm{Ct}$ method was used to compare gene expression data; means \pm standard error of the mean (SEM) was calculated The effect of unrelated oligonucleotides was also reported. " $\mathrm{P}<0.05$. The localization of the potential binding sites for NFATc1 in the 5 ' regulatory regions of human ER $\alpha$, Runx2 and ColXV genes are reported.

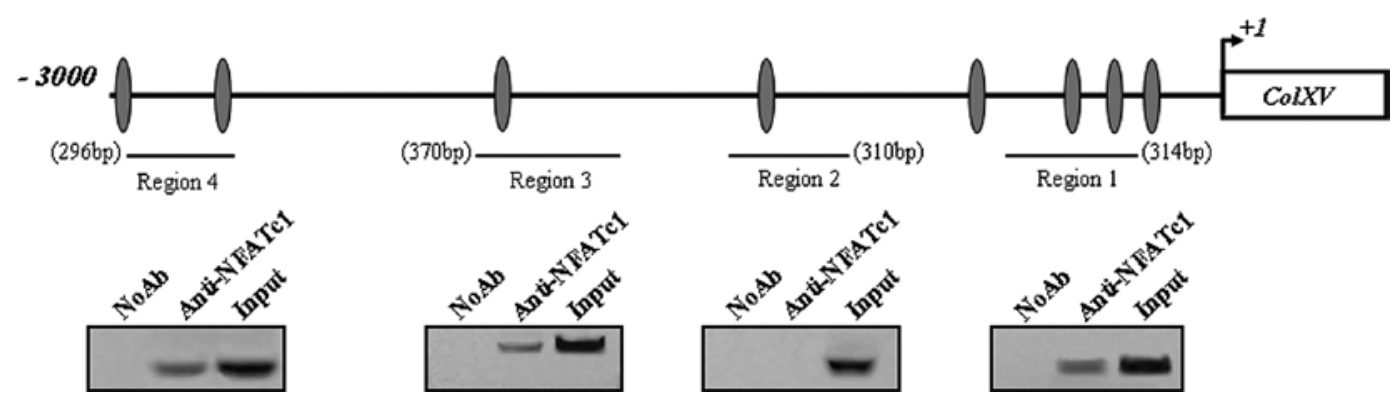

Figure 5. NFATc1 binds the human ColXV promoter in vivo. The ColXV promoter region under investigation is reported (+1 to -3000$)$. The positions of the putative NFATc1 consensus binding sites are enclosed by gray ovals. Recruitment of the NFATc1 transcription factor to the human ColXV promoter was demonstrated by in vivo ChIP binding assays. Soluble chromatin was prepared from hOBs and immunoprecipitated with the specific antibody against NFATc1. The association of the transcription factor on the regions 1-4 of the human ColXV promoter was analyzed by PCR using primer pairs spanning the reported regions of ColXV promoter. The specific molecular weights of PCR fragments are shown in parentheses. No Ab, negative control; Input, a positive control using the starting material $(0.2 \%)$ prior to the immunoprecipitation. Representative agarose gels are shown.

DNA, and sonicated to fragment the chromatin. A specific antibody against NFATc1 was used to immunoprecipitate the protein DNA complexes. The presence of the promoterspecific DNA region before immunoprecipitation was confirmed by PCR (Input). After immunoprecipitation, DNA was extracted from the beads and used as a template to generate specific PCR products spanning the putative NFATc1 binding sites from -3000 bp to $+1 \mathrm{bp}$ in the promoter of the ColXV gene. NFATc1 recruitment was assessed at the different promoter regions by using specific sets of primers (Table I). As shown in Fig. 5, NFATc1 occupancy was detected at the regions 1,3 and 4, but not at region 2. This demonstrated that ColXV is a specific NFATc1 target gene in human osteoblasts.

\section{Discussion}

To our knowledge, the results of the present study establish, for the first time, that removal of the NFATc1 transcription factor by a decoy approach in hOBs induces the expression of ER $\alpha$ and ColXV that are positively correlated with osteoblastic differentiation. These findings have a double meaning: on the one hand, they reinforce the role of this factor in the transcriptional program of osteoblasts, on the other they contribute important information on ColXV which only recently has been proposed as an osteoblastic marker (30). In addition, the present study in agreement with several published reports $(17,18,21-23,31-33)$ supports the potential utility of the decoy strategy to treat specific diseases. It is 
well known that synthetic double-stranded ODN as decoy cis elements block the binding of nuclear factors to promoter regions of targeted genes, resulting in the modulation of gene expression. The interest in this approach is supported by studies correlating the altered activity of transcription factors with specific diseases $(34,35)$.

NFATc1 is referred to as the key transcription factor in osteoclastogenesis (36); however, several lines of evidence indicate that it regulates bone mass by functioning not only in osteoclasts but also in osteoblasts $(6,7)$. In fact, it has recently been shown that NFATc1 contributes to the regulation of osteoblastic specific genes including Osterix (8) and Fra-2 (37), modulates the activity of ligands for osteoclastassociated receptors such as OSCAR (38) primarily produced by osteoblasts, and is involved in the transcriptional regulation of the ER $\alpha$ gene in the SaOS-2 osteosarcoma cell line (24).

Here we have demonstrated that hOBs efficiently respond to NFATc1 decoy treatment in terms of an increase in ER $\alpha$ gene expression. This evidence may be correlated with an increased potential for cell sensitivity to estrogens and consequently an improvement in osteoblast differentiation. Actually, the positive effect of estrogen on bone metabolism is well known (39). These considerations substantiate the interest in NFATc1 as a promising therapeutic target that could be employed for the development of anabolic agents for the treatment of bone loss. This conclusion is supported by the evidence that decoy-treated hOBs showed a significant increase in ColXV mRNA levels. Interestingly, the expression of ColXV, was recently demonstrated in human osteoblasts both in vitro and in vivo (30).

In addition, a direct involvement of this molecule in the mineralization process of mesenchymal stem cells induced to osteogenesis and in bone tissue remodelling has been suggested (30). 5'-Regulatory sequences of the ColXV gene promoter have been only partially characterized (40) and, until now, it is known that its expression is modulated by exogenous calcium induction. Our results demonstrate, for the first time, a specific in vivo interaction of NFATc1 with specific sequences of the ColXV gene promoter suggesting a direct involvement of NFATc1 during osteoblastogenesis. Therefore, even if further studies are required to investigate the molecular mechanism of action of NFATc1, the novelty of our findings provide insight into the regulation of the ColXV gene transcription, ascribing to NFATc1 a role of negative transcription factor.

Regarding the therapeutic potential of the decoy experimental approach for bone diseases, it is worth noting that NFATc1 is utilized in both bone-forming and bone-resorbing cells. Therefore, the decoy against NFATc1 in the bone microenviroment may be effective for treating bone diseases exerting positive and negative action on osteoblasts and osteoclasts, respectively. Based on these considerations, the decoy against NFATc1, working upstream of the transcription machinery, may prove to be a gene-targeted tool for treating skeletal disorders caused by excessive bone resorption, including osteoporosis and destructive bone metastasis. In addition, considering that NFATc1 cooperates with other transcription factors, the here described approach may help to shed light on upstream signal-transduction networks that may lead to altered transcription programs in bone cells. In particular, after translocation to the nucleus and DNA binding, NFATc1 protein facilitates the binding of AP-1 to NFAT-AP-1 binding sites whereupon the AP-1 components can mediate the induction of transcription (13). As AP-1 family members play a key role in the regulation of bone-specific genes and consequently in osteoblast differentiation (41), the interaction with NFATc1 is particularly relevant in the bone microenvironment. In this regard, it will be useful to further investigate the recruitment of the AP-1 family members at the ColXV gene promoter by ChIP analysis.

In conclusion, to the best of our knowledge this is the first time that TFD has been successful in hOBs allowing the investigation of the role of NFATc1 in an experimental model that compared to cell lines more closely resembles an in vivo model. In addition, our results provide new insight into the regulation of osteoblastic markers and strengthen the therapeutic potential of the decoy approach to treat skeletal disorders by properly manipulating NFATc1-mediated cellular events.

\section{Acknowledgements}

This research was supported by grants from MIUR-Cofin 2007; Regione Emilia Romagna, 'Programma di Ricerca Regione Universita' 2007-2009; the 'Fondazione Cassa di Risparmio di Padova e Rovigo'. E.L. is a recipient of a fellowship from the 'Fondazione Cassa di Risparmio di Ferrara'.

\section{References}

1. Rodan GA and Martin TJ: Therapeutic approaches to bone diseases. Science 289: 1508-1514, 2000

2. Kwan MD, Slater BJ, Wan DC and Longaker MT: Cell-based therapies for skeletal regenerative medicine. Hum Mol Genet 17: 93-98, 2008.

3. Sitara D and Aliprantis AO: Transcriptional regulation of bone and joint remodeling by NFAT. Immunol Rev 233: 286-300, 2010.

4. Fromigué O, Haÿ E, Barbara A and Marie PJ: Essential role of nuclear factor of activated T cells (NFAT)-mediated Wnt signaling in osteoblast differentiation induced by strontium ranelate. J Biol Chem 285: 25251-25258, 2010.

5. Choo MK, Yeo H and Zayzafoon M: NFATc1 mediates HDACdependent transcriptional repression of osteocalcin expression during osteoblast differentiation. Bone 45: 579-589, 2009.

6. Stern PH: The calcineurin-NFAT pathway and bone: intriguing new findings. Mol Interv 6: 193-196, 2006.

7. Winslow MM, Pan M, Starbuck M, Gallo EM, Deng L, Karsenty G and Crabtree GR: Calcineurin/NFAT signaling in osteoblasts regulates bone mass. Dev Cell 10: 771-782, 2006.

8. Koga T, Matsui Y, Asagiri M, Kodama T, de Crombrugghe B, Nakashima K and Takayanagi H: NFAT and Osterix cooperatively regulate bone formation. Nat Med 11: 880-885, 2005.

9. Hogan PG, Chen L, Nardone J and Rao A: Transcriptional regulation by calcium, calcineurin, and NFAT. Genes Dev 17: 2205-2232, 2003.

10. Wu H, Peisley A, Graef IA and Crabtree GR: NFAT signaling and the invention of vertebrates. Trends Cell Biol 17: 251-260, 2007.

11. Im SH and Rao A: Activation and deactivation of gene expression by $\mathrm{Ca}^{2+} /$ calcineurin-NFAT-mediated signaling. Mol Cells 18: $1-9,2004$

12. Bert AG, Johnson BV, Baxter EW and Cockerill PN: A modular enhancer is differentially regulated by GATA and NFAT elements that direct different tissue-specific patterns of nucleosome positioning and inducible chromatin remodeling. Mol Cell Biol 27: 2870-2885, 2007.

13. Macián F, López-Rodríguez C and Rao A: Partners in transcription: NFAT and AP-1. Oncogene 20: 2476-2489, 2001. 
14. Yang G, Yu F, Fu H, Lu F, Huang B, Bai L, Zhao Z, Yao L and $\mathrm{Lu} \mathrm{Z}$ : Identification of the distinct promoters for the two transcripts of apoptosis related protein 3 and their transcriptional regulation by NFAT and NFkappaB. Mol Cell Biochem 302: 187-194, 2007.

15. Yang XY, Wang LH, Chen T, Hodge DR, Resau JH, DaSilva L and Farrar WL: Activation of human T lymphocytes is inhibited by peroxisome proliferator-activated receptor gamma (PPARgamma) agonists. PPARgamma co-association with transcription factor NFAT. J Biol Chem 275: 4541-4544, 2000.

16. Borgatti M, Boyd DD, Lampronti I, Bianchi N, Fabbri E, Saviano M, Romanelli A, Pedone C and Gambari R: Decoy molecules based on PNA-DNA chimeras and targeting Sp1 transcription factors inhibit the activity of urokinase-type plasminogen activator receptor (UPAR) promoter. Oncol Res 15: 373-383, 2005.

17. Mann MJ and Dzau VJ: Therapeutic application of transcriptional factor decoy oligonucleotides. J Clin Invest 106 1071-1075, 2000

18. Morishita R, Sugimoto T, Aoki M, Kida I, Tomita N, Moriguchi A, Maeda K, Sawa Y, Kaneda Y, Higaki J and Ogihara T: In vivo transfection of cis element 'decoy' against nuclear factor- $\kappa \mathrm{B}$ binding site prevents myocardial infarction. Nat Med 3: 894-899, 1997.

19. Piva R, Penolazzi L, Lambertini E, Giordano S and Gambari R: Induction of apoptosis of human primary osteoclasts treated with a transcription factor decoy mimicking a promoter region of estrogen receptor alpha. Apoptosis 66: 1079-1094, 2005.

20. Lui VW, Boehm AL, Koppikar P, Leeman RJ, Johnson D, Ogagan M, Childs E, Freilino M and Grandis JR: Antiproliferative mechanisms of a transcription factor decoy targeting signal transducer and activator of transcription (STAT) 3: the role of STAT1. Mol Pharmacol 71: 1435-1443, 2007.

21. Bezzerri V, Borgatti M, Nicolis E, Lampronti I, Dechecchi MC, Mancini I, Rizzotti P, Gambari R and Cabrini G: Transcription factor oligodeoxynucleotides to NF-kappaB inhibit transcription of IL-8 in bronchial cells. Am J Respir Cell Mol Biol 39: 86-96, 2008.

22. Moriyama I, Ishihara S, Rumi MA, Aziz MD, Mishima Y, Oshima N, Kadota C, Kadowaki Y, Amano Y and Kinoshita Y: Decoy oligodeoxynucleotide targeting activator protein-1 (AP-1) attenuates intestinal inflammation in murine experimental colitis. Lab Invest 88: 652-663, 2008.

23. Gambari R, Borgatti M, Bezzerri V, Nicolis E, Lampronti I, Dechecchi MC, Mancini I, Tamanini A and Cabrini G: Decoy oligodeoxyribonucleotides and peptide nucleic acids-DNA chimeras targeting nuclear factor kappa-B: Inhibition of IL-8 gene expression in cystic fibrosis cells infected with Pseudomonas aeruginosa. Biochem Pharmacol 80: 1887-1894, 2010.

24. Penolazzi L, Zennaro M, Lambertini E, Tavanti E, Torreggiani E, Gambari R and Piva R: Induction of estrogen receptor alpha expression with decoy oligonucleotide targeted to NFATc1 binding sites in osteoblasts. Mol Pharmacol 71: 1457-1462, 2007.

25. Deroo BJ and Korach KS: Estrogen receptors and human disease. J Clin Invest 116: 561-570, 2006.

26. Lambertini E, Lisignoli G, Torreggiani E, Manferdini C, Gabusi E, Franceschetti T, Penolazzi L, Gambari R, Facchini A and Piva R: Slug gene expression supports human osteoblast maturation. Cell Mol Life Sci 66: 3641-3653, 2009.
27. Dignam JD, Lebovitz RM and Roeder RG: Accurate transcription initiation by RNA polymerase II in a soluble extract from isolated mammalian nuclei. Nucleic Acids Res 11: 1475-1489, 1983.

28. Manzati E, Aguiari G, Banzi M, Manzati M, Selvatici R, Falzarano S, Maestri I, Pinton P, Rizzuto R and del Senno L: The cytoplasmic C-terminus of polycystin-1 increases cell proliferation in kidney epithelial cells through serum-activated and $\mathrm{Ca}(2+)$-dependent pathway(s). Exp Cell Res 304: 391-406, 2005.

29. Tonnarelli B, Manferdini C, Piacentini A, Codeluppi K, Zini N, Ghisu S, Facchini A and Lisignoli G: Surface-dependent modulation of proliferation, bone matrix molecules, and inflammatory factors in human osteoblasts. J Biomed Mater Res 89: 687-696, 2008.

30. Lisignoli G, Codeluppi K, Todoerti K, Manferdini C, Piacentini A, Zini N, Grassi F, Cattini L, Piva R, Rizzoli V, Facchini A, Giuliani N and Neri A: Gene array profile identifies collagen type $\mathrm{XV}$ as a novel human osteoblast-secreted matrix protein. J Cell Physiol 220: 401-409, 2009.

31. Han W and Liu GN: EGR-1 decoy ODNs inhibit vascular smooth muscle cell proliferation and neointimal hyperplasia of balloon-injured arteries in rat. Arterioscler Thromb Vasc Biol 29: 1080-1086, 2009

32. Aoki T, Kataoka H, Ishibashi R, Nozaki K, Morishita R and Hashimoto N: Reduced collagen biosynthesis is the hallmark of cerebral aneurysm: contribution of interleukin-1beta and nuclear factor-kappaB. Life Sci 86: 234-243, 2010.

33. Stadlbauer TH, Wagner AH, Hölschermann H, Fiedel S, Fingerhuth H, Tillmanns H, Bohle RM and Hecker M: AP-1 and STAT-1 decoy oligodeoxynucleotides attenuate transplant vasculopathy in rat cardiac allografts. Cardiovasc Res 79: 698-705, 2008

34. Semenza GL: Transcription Factors and Human Disease. Oxford Monographs on Medical Genetics. 1st edition. Oxford University Press, New York, 1998.

35. Blancafort P, Segal DJ and Barbas CF III: Designing transcription factor architectures for drug discovery. Mol Pharmacol 66: 1361-1371, 2004

36. Takayanagi $\mathrm{H}$ : The role of NFAT in osteoclast formation. Ann NY Acad Sci 1116: 227-237, 2007.

37. Zayzafoon M: Inhibition of NFAT increases osteoblast differentiation by increasing Fra-2 expression. J Musculoskelet Neuronal Interact 5: 347, 2005

38. Kim JH, Kim K, Youn BU, Jin HM and Kim N: MHC class II transactivator negatively regulates RANKL-mediated osteoclast differentiation by downregulating NFATc1 and OSCAR. Cell Signal 22: 1341-1349, 2010

39. Zallone A: Direct and indirect estrogen actions on osteoblasts and osteoclasts. Ann NY Acad Sci 1068: 173-179, 2006

40. Eklund L, Muona A, Liétard J and Pihlajaniemi T: Structure of the mouse type XV collagen gene, Col15a1, comparison with the human COL15A1 gene and functional analysis of the promoters of both genes. Matrix Biol 19: 489-500, 2000

41. Bozec A, Bakiri L, Jimenez M, Schinke T, Amling M and Wagner EF: Fra-2/AP-1 controls bone formation by regulating osteoblast differentiation and collagen production. J Cell Biol 190: 1093-1106, 2010 